\title{
EL ROL POLÍTICO DEL JUICIO LEGAL Y EL CASTIGO. UN ANÁLISIS DESDE LA FILOSOFÍA DE HANNAH ARENDT
}

The political role of legal trials and punishment: An analysis from Hannah Arendt's philosophy

\author{
María Soledad Sanhueza \\ Universidad Alberto Hurtado/Universidad Diego Portales \\ m.solesanhueza@gmail.com
}

\section{Resumen}

En el presente artículo hacemos una reflexión desde el pensamiento de Hannah Arendt, sobre la importancia política que tiene el juicio legal llevado a cabo en los Tribunales, sobre todo luego de episodios horrorosos como son las dictaduras. Esta importancia radica en que el juicio legal y el castigo son momentos del proceso de «reconciliación política», el cual permite que la vida política se restaure y continúe existiendo luego de que se han cometido crímenes contra la comunidad.

Palabras clave: juicio legal, castigo, reconciliación, responsabilidad, Hannah Arendt.

\begin{abstract}
In the following article, a reflection is made based on Hannah Arendt's ideas about the political importance of legal trial conducted in courts, specially after horrible episodes such as dictatorships. The aforementioned importance lies in the fact that legal trial and punishment are moments that are part of the "political reconciliation", which allows the restauration and continued existence of the political life after commiting crimes against the community.
\end{abstract}

Keywords: legal trial, punishment, reconciliation, responsibility, Hannah Arendt.

Fecha de Recepción: 10/03/2019 - Fecha de Aceptación: 22/04/2019 
Cuando fueron agentes del Estado los que ocasionaron tanto sufrimiento, y los órganos competentes del

Estado no pudieron o no supieron evitarlo o sancionarlo, y tampoco hubo la necesaria reacción social para impedirlo, son el Estado y la sociedad entera los responsables, bien sea por acción o por omisión. Es la sociedad chilena la que está en deuda con las víctimas de las violaciones de derechos humanos

Patricio Aylwin, 1991, al dar a conocer a la ciudadanía el Informe de la Comisión de Verdad y Reconciliación

Soy persona inocente, y fui absuelta dos veces. Estoy molesta, porque hay personas condenadas porque pusieron plata los latifundistas. Por plata se mueven los jueces (...) está bien que busquen la justicia, pero que busquen a los culpables, y que no condenen a los inocentes

Machi Francisca Linconao, luego de ser absuelta por tercera vez en el caso Lucksinger-Mackay

\section{Introducción}

He decidido escribir sobre castigo e impunidad, porque es una dupla de contrarios que conocemos muy bien como chilenos, tanto por nuestra historia cercana -que viene enfrentando hasta ahora ambos conceptos con respecto a los crímenes contra los derechos humanos cometidos durante la dictadura cívico-militar- como por lo que día a día vemos, discutimos, pensamos y escuchamos, frente a los crímenes que se cometen en nuestro barrio, nuestra ciudad y nuestro país: se pide justicia, se alega inocencia, se reclama protección de parte de los poderes del Estado. Definitivamente, las palabras "crimen", "delito" y "agravio", tienen significado negativo y los actos criminales nos provocan sentimientos, pensamientos y discursos negativos: nos intimidan, nos producen repudio, tratamos de evitarlos, apelamos a las responsabilidades que tienen las autoridades para evitarlos e incluso apelamos a nuestro propio derecho a defendernos. En resumen, los crímenes afectan individualmente a quienes son víctimas de ellos, pero por sobre todo nos afectan como comunidad política y es en nuestra calidad de integrantes de una comunidad política, que esperamos una respuesta frente a ellos. Parece que los crímenes no son acontecimientos que se espera que ocurran en una comunidad que se ha organizado políticamente y por ello nos molestan ${ }^{1}$.

Por esta relación entre los crímenes, la víctima y la comunidad política, en el siguiente trabajo profundizaremos en el rol político que tiene el juicio legal y el consecuente castigo, todo lo anterior a partir del pensamiento de Hannah Arendt. Las injusticias son una posibilidad dentro del mundo de los asuntos humanos, pero esta posibilidad tiene un remedio, la capacidad de reconciliación política, que solo se puede dar si media un castigo legal hacia quien cometió la injusticia

\footnotetext{
${ }^{1}$ El porqué los crímenes no solo nos afectan individualmente es un tema que revisaremos en el texto.
} 
respectiva. De no existir la posibilidad de reconciliación el, mundo político tendría fecha de término.

Resulta necesario decir que los crímenes que se cometen al interior de una comunidad política no atentan solo contra la víctima, sino que atentan contra la comunidad completa: quiebran la trama de los asuntos humanos y, por lo tanto, impiden establecer vínculos políticos (libres) entre los integrantes de la comunidad. La reconciliación política nos permite reconstruir en parte esa trama, y para ello necesitamos castigar a los culpables de los delitos. Es mediante la declaración de culpabilidad y dictación de sentencia, como se restituye la confianza en la promesa que es la ley, la cual, es la herramienta política que consigue que los seres humanos, distintos siempre, nos reconozcamos como seres iguales pertenecientes a una comunidad. De este modo es que sin confianza en la ley, no puede haber comunidad política.

Como se puede ver, este texto no corresponde a un trabajo de derecho, sino a una reflexión filosófica respecto a justicia e impunidad.

Primero expondré brevemente el modo en que se conforma una comunidad política y el espacio relevante que tiene en ella la ley como promesa que torna previsibles las acciones de los seres humanos. Luego desarrollaré la idea de reconciliación política que Arendt presenta en su Diario Filosófico. En tercer lugar hablaré de la distinción que hace Arendt entre "responsabilidad" y "culpa" al momento de enfrentar los crímenes, y mostraré que sólo la culpa es punible. El cuarto aspecto que desarrollaré será la facultad de juzgar: su importancia para la política y la relación que tiene con el juicio legal y la asignación de culpabilidad. Ya para concluir expondré la importancia que tiene para la política, dentro del pensamiento arendtiano, el juicio legal y el castigo.

\section{La construcción de una comunidad política y los lazos de la justicia.}

Siguiendo el pensamiento de Hannah Arendt, la política es una actividad que los seres humanos realizan no por necesidad sino por libertad y en libertad (Arendt 2005a 35; 1996 160). De todas las actividades que realizamos los seres humanos, existen dos que cumplen con esa característica: la acción (praxis) y el discurso (lexis) (Arendt 2005a 39-40), las cuales realizamos porque la vida humana ocurre bajo ciertas condiciones. La condición de ser nacidos - de ser un nuevo inicio en el mundo - es lo que nos impulsa a realizar acciones (o iniciar acciones si se prefiere) (Arendt 2005a 206-207) y, la condición de la pluralidad es la que nos impulsa a decir cosas de tal forma que generemos lazos con los otros a través de la palabra: hacemos discursos porque no somos iguales, pero como no somos completamente distintos -o porque nos reconocemos con alguna igualdad- es que podemos hacer 
discursos que nos permitan llegar a acuerdos, que nos permitan darnos a entender y que nos permitan revelarnos frente a otros (Arendt 2005a 207).

Con esta descripción inicial de la política nos podemos dar cuenta de que esta actividad dista mucho se asemejarse a "el arte de gobernar" que es como la RAE define política, o incluso la organización estructurada en la que pensamos cuando decimos la palabra gobierno: las acciones y los discursos son actividades completamente fútiles e incluso caóticas. Ninguna pertenece al reino de la verdad sino de la opinión y no se pueden controlar. Tratar de controlar la praxis y la lexis quita a estas actividades del ámbito de la libertad $\mathrm{y}$, por lo tanto, las quita del espacio político. Las acciones y los discursos se caracterizan por ser imprevisibles, irreversibles y anónimos (Arendt 2005a 242). Precisamente, por estas características de la actividad política es que, la única forma en que se le logra dar estabilidad y permanencia a la acción, y a la política misma, es a través de la conformación de una comunidad política que tenga cierta permanencia en el tiempo. Esta permanencia, está dada por elementos que no son políticos específicamente, pero que sí son necesarios para que ella exista, como son la frontera y la ley. Es para hacer frente a la fragilidad de los asuntos humanos que -según Arendt- los griegos crearon la polis, como una forma de comunidad política que permite dar cierta estabilidad y permanencia a los asuntos humanos (Arendt 2005a 220). La polis no es sólo una comunidad política, sino que es una comunidad que limita el accionar de los seres humanos a través de ciertas condiciones que no pertenecen a la actividad política propiamente tal. Estas son: la muralla que marca el límite territorial de la ciudad-estado, y las leyes que marcan el límite para la acción.

Con respecto a la vida política de los seres humanos (compartir palabras y acciones), la polis tenía una doble función. La primera era otorgar una estructura que permitiera que lo extraordinario se pudiera convertir en ordinario. Es decir, capacitaba a los seres humanos para que de forma permanente pudieran adquirir fama por sus acciones, ya que la polis era un espacio idóneo -representaba el espacio público- para que se realizaran las actividades políticas. La segunda función, era ofrecer un remedio a la futilidad de los asuntos humanos, ya que solo la polis podía asegurar que las actividades más fútiles de los seres humanos, como son los asuntos humanos, y sus «productos» (las historias) fueran imperecederos (Arendt 2005a 223), ya que en una comunidad organizada las acciones adquieren sentido y también pueden ser presenciadas por otros. Existe la posibilidad del recuerdo y de la interpretación.

Sin embargo hay que tener en cuenta que la polis no era el espacio que estaba delimitado por el muro que marcaba la frontera (espacio físico), ni por el límite que demarcaban las leyes: tanto las leyes como la frontera no eran consideradas parte de la dimensión política (Arendt 2005a 221-222). La polis era la 
organización de la gente, tal como surge de actuar y hablar juntos, y su espacio se extiende entre las personas que viven juntas para este propósito. Así, la polis era la trama de asuntos humanos a la que, posteriormente, limitaba el muro de la ciudad y demarcaba las leyes. Para Arendt, en la Grecia clásica quien hacía las leyes de una comunidad política no era necesariamente un ciudadano, sino que era un artesano.

De este modo, es que tenemos que considerar que la ley funciona como un límite tal como ocurre con la frontera física: la frontera física delimita un territorio en el que está situada una comunidad política, pero también muestra hasta donde se extiende la misma ley que se ha forjado. La frontera física también muestra la extensión de la igualdad y de la construcción del "nosotros" que implica la conformación de una comunidad (Arendt 2005a 238), y también representa una frontera de sentido para las acciones y los discursos de las personas que viven dentro de esas fronteras (Arendt 2005a 218). Las comunidades funcionan como una suerte de recuerdo organizado y la frontera territorial enmarca ese recuerdo (Arendt 2005a 224). En cambio, la ley corresponde a una frontera de acción y también a una promesa que nos congrega. Si bien hemos dicho anteriormente que la acción es irreversible e imprevisible, hay una forma de poner remedio a esta suerte de condena a la que nos somete la política (esa condena de no controlar las consecuencias de nuestras acciones y de no poder preveerlas): el perdón y la promesa (Arendt 2005a 256).

Hacer promesas involucra hacer previsible una acción, aunque nunca hay certeza del cumplimiento de las promesas, pues nunca hay certezas en el mundo de los asuntos humanos, lo único que queda en ese caso es la confianza: sin estar obligados a cumplir nuestras promesas vagaríamos sin dirección fija, sin poder predecir nada (Arendt 2005a 257). La ley formaría parte de este conjunto de promesas que se realizan en una comunidad política. Las leyes tornan previsibles las acciones de las personas y permiten darles cierta permanencia, así se hace mucho más llevadera la vida en comunidad. Es por ello que los crímenes vendrían a ser la ruptura de las promesas y el retorno de la imprevisibilidad absoluta al ámbito de los asuntos humanos, y por lo mismo la fragilización de los lazos que se forman entre las personas que componen la comunidad, pues estos, en gran medida están conformados por la confianza. De este modo, los crímenes no son una afrenta directa hacia la víctima, sino una afrenta hacia la comunidad y la organización que ella misma dispuso, así como también una afrenta hacia las relaciones de confianza que se pueden llegar a establecer en el mundo de los asuntos humanos.

Si los crímenes son una afrenta hacia la comunidad y las relaciones humanas, lo son también hacia la organización política y la estabilidad de estas 
mismas relaciones y los castigos frente a esos crímenes vienen a ser el intento de recomponer la trama de relaciones humanas fracturada y también a recomponer esa promesa que vuelve las acciones previsibles, esto es, a la ley.

¿Cómo tratar de recomponer estas relaciones humanas? A través del perdón

(o de la reconciliación). "La posible redención del predicamento de la irreversibilidad [...] es la facultad de perdonar. El remedio de la imposibilidad de predecir, se halla en la facultad de hacer y mantener las promesas" (Arendt 2005a 256). Sin ser perdonados, liberados de las consecuencias de un acto, la capacidad de actuar de los hombres quedaría atada a un solo acto. Sin estar obligados a cumplir nuestras promesas vagaríamos sin dirección fija, sin poder predecir nada (Arendt 2005a 257). Ambas facultades dependen de la pluralidad, de la presencia y acción con otros, pues nadie puede perdonarse a sí mismo ni sentirse ligado a cumplir una promesa que sólo se ha hecho a sí mismo.

El perdón es lo contrario de la venganza. Ésta no quiere poner fin al proceso iniciado por la acción, y permite que la reacción en cadena siga su curso libremente: la venganza es la reacción previsible que tendría un individuo frente a un agravio. En cambio el perdón es imprevisible y no es sólo una reacción, sino que también una nueva acción libre y no condicionada por la acción que la originó (Arendt 2005a 259). La alternativa al perdón es el castigo, aunque no su contrario, pues ambos tratan de poner fin a algo que sin interferencia sería inacabable (Arendt 2005a 260). Por lo tanto, la esfera de los asuntos humanos tiene como elemento estructural -ya que el perdón y el castigo se refieren a la interferencia de un proceso- el que los hombres no puedan perdonar lo que no pueden castigar y viceversa. Los hechos que son imperdonables y que no se pueden castigar, se apartan de los asuntos humanos y le quitan todo poder de acción a los seres humanos (Arendt 2005a 260).

Si el perdón y el castigo es lo que nos permite poner fin a una acción, la promesa -como vimos- es la que nos permite darle cierta previsibilidad a los actos humanos, pero para actualizar esta facultad es necesario estar entre otros hombres.

La inhabilidad del hombre para confiar en sí mismo o para tener fe completa en sí mismo (que es la misma cosa) es el precio que los seres humanos pagan por la libertad; y la imposibilidad de seguir siendo dueños únicos de lo que hacen, de conocer sus consecuencias y confiar en el futuro es el precio que les exige la pluralidad y la realidad, por el júbilo de habitar junto con otros un mundo cuya realidad está garantizada para cada uno por la presencia de todos (Arendt 2005a 262).

Dañar a otros es una posibilidad de las acciones humanas y es el precio de la libertad en la que ocurren las relaciones humanas. Ahora bien, existe la posibilidad de vivir en un mundo donde las injusticias son posibles, que no es lo mismo que decir que vivimos en un mundo injusto. El perdón y la promesa son las formas en 
que, la posibilidad de injusticia es salvada y podemos continuar construyendo en el mundo de los asuntos humanos.

Respecto al castigo como alternativa al perdón Arendt no profundiza más en sus textos. Aunque sí logra dar una solución política a los daños que se producen gracias a la acción en el mundo de los asuntos humanos, y esta solución va de la mano con la reconciliación. Al parecer, el perdón no representa una solución política y tampoco representa un hito que se puede hacer como comunidad. El perdón es un gesto entre individuos que permite ponerle fin a una cadena de acciones infinita, pero no un acto de comunidad. En cambio, la reconciliación es un fenómeno político que se realiza en comunidad y de este fenómeno el castigo es parte.

\section{La reconciliación como la forma de enfrentar la injusticia}

En el Diario Filosófico Arendt diferencia tres formas en las que un ser humano responde frente a un acto que le ha causado daño: el perdón, la reconciliación y la venganza.

El perdón es el acto que realiza dios para con los hombres, es decir, es un acto que requiere asimetría y separación cualitativa entre quien perdona y quien es perdonado. De este modo el perdón no se puede realizar en el ámbito de los asuntos humanos, que existe sobre la base de la igualdad y pluralidad entre los hombres (Arendt 2006 3). El acto de perdonar implica una gran cuota de pasividad, la que impide hacer frente a los hechos agraviantes que han ocurrido, y más bien hace que estos agravios se asuman en forma silenciosa y resignada, tal como si no hubieran ocurrido jamás (Arendt 2006 4). Esta noción de perdón que encontramos en el Diario Filosófico, Arendt la vincula con las ideas que ella tiene de justicia y pecado, vínculo que hace que el perdón se aleje de los asuntos humanos.

Pecado es una noción judeocristiana que ubica en la naturaleza humana la posibilidad del mal y del error. Esta posibilidad es una mancha (pecado original) que queda en el hombre por el error de Adán y Eva de comer del árbol del conocimiento. El conflicto que le produce a Arendt que el pecado esté relacionado con la naturaleza humana, viene dado porque el pecado, que sería la fuente del error de los seres humanos, se encuentra al interior de ellos y no en el mundo y en sus actos. Por lo tanto, quien perdona renuncia a vengarse porque ve que él también pudo cometer la falta que está perdonando, por poseer la misma naturaleza de pecador que quien ha cometido la falta. También hay que considerar que sólo dios puede perdonar nuestros pecados, por lo que cuando un ser humano perdona, trata, de alguna forma, de imitar a dios y no de mantenerse entre sus iguales. 
La justicia, por su parte, es una virtud política. Esto significa que sólo se puede ser justo en el ámbito de los asuntos humanos, que es donde existe igualdad. De este modo se forma una diferencia sustancial entre el pecado y lo injusto, ya que, como dijimos, el pecado se encuentra en el interior del hombre, en cambio la injusticia está sobre los hombres; es decir, la injusticia es una posibilidad que existe porque los hombres actúan, y la acción se realiza en el mundo y sólo en compañía de otros hombres, esto es, fuera del individuo.

En el Diario filosófico la venganza sigue en el polo opuesto al perdón, pues no olvida ni pasa de largo, sino que siempre está al acecho y permanece cerca de la acción dañina y de su actor. Quien se venga actúa en contra, porque, al reconocer el mal en el interior del ser humano, puede hacer lo que a él le han hecho y tomar posición de victimario tal como antes tomó la posición de víctima.

Entre el perdón y la venganza, extremos que no permiten el juicio, se encuentra la dimensión de la reconciliación. Sólo mediante ella podemos poner sobre nuestros hombros la carga y la falta que ha cometido el otro, y de esta forma restablecer la igualdad. De esta manera la reconciliación -que es la forma de actuar frente a los actos dañinos, al reconocer estos actos como una posibilidad del mundo inter homines- tiene como producto la solidaridad, pues ella permite reconocer que las faltas de los seres humanos se producen por su capacidad de acción. Es decir, permite reconocer que en el mundo político siempre está latente la posibilidad de los actos injustos (Arendt 2006 4, 6).

La solidaridad elimina la culpa compartida y la idea que deja la noción de pecado de que "cualquiera podría haber cometido esto" (y con esta idea la consecuente imposibilidad de juicio) (Arendt 2006 6). Ese es el lado piadoso de la reconciliación. Sin embargo, la reconciliación también es la que nos permite hacer juicios sobre las acciones de los seres humanos, y además decir "esto no debería haber ocurrido nunca". Acá nos enfrentamos a una doble noción de juicio: la primera noción se refiere a lo que podemos llamar el juicio legal, que tiene directa relación con la idea de justicia y castigo. La segunda noción es la de la facultad de juzgar: para Arendt, la facultad más política de todas.

Así, reconciliarse es hacer frente a los acontecimientos injustos -e incluso horrorosos- que pueden haber ocurrido en el pasado de nuestra comunidad política, y reconocerlos como fruto de una posibilidad latente en la acción de los hombres (de su «hacer política»), y aun así ser solidario y, junto a la comunidad, aceptar llevar la carga de estos actos, la cual también llevan quienes cometieron las injusticias.

De este modo la reconciliación se presenta como un acto comunitario, donde la comunidad no asume la culpa de los crímenes cometidos -pues la culpa es individual y jamás colectiva- sino que acepta una cierta responsabilidad sobre los 
hechos acontecidos, pero también se permite hacer justicia y tratar de restituir la trama de los asuntos humanos que ha sido rota mediante un delito.

\section{Distinción entre responsabilidad y culpa}

Frente a un crimen distinguir la culpa de la inocencia no requiere mayores esfuerzos, fuera de los propios de una investigación judicial. Pero no ocurre lo mismo al momento de diferenciar entre culpa y responsabilidad. El asunto es importante, pues de ello dependerá que un acto sea o no punible, y de que podamos identificar a quién se le puede llamar culpable y a quién no. De base hay que partir diciendo que los responsables no se juzgan, pero que los culpables sí. La culpa -aquello por lo que se juzga a una persona ante un tribunal- sólo es individual, mientras que la responsabilidad puede ser tanto individual como colectiva. De esta manera, uno no puede culpar a alguien por actos en los que no participó directa, consciente y voluntariamente, pues si así fuese podría llegarse al extremo en el que, como dice Arendt, "si todos somos culpables nadie lo es" (Arendt 2005b 41; 2007a 58), lo que impediría establecer una línea divisoria entre el culpable y el inocente de un crimen. El ejemplo más claro esto nos lo presenta la literatura en el caso de Fuenteovejuna.

De este modo la culpa no se comparte y solo son culpables las personas que deciden voluntariamente realizar un agravio. Lo que sí se puede compartir respecto de un crimen es la responsabilidad, la cual se vincula a la participación y, por lo tanto, trasciende a la voluntad y la conciencia. La forma en que entendemos participación en este sentido es amplia: participamos en los actos incluso cuando lo hacemos de forma inconsciente o no voluntaria, de igual forma participamos cuando fuimos testigos de un agravio, incluso participamos en los actos cuya historia heredamos ${ }^{2}$. Este sentido amplio de participación no implica culpabilidad, y por lo tanto no es punible, sino que en este caso solo hablamos de responsabilidad: estamos vinculados con un agravio, ya sea de forma estrecha o más laxa, pero nuestras acciones no han producido el agravio mismo.

A la dimensión colectiva de la responsabilidad -que es la forma más laxa e impersonal de responsabilidad- la llamamos responsabilidad política y es cuando se le atribuye responsabilidad a alguien de un acto, sólo porque pertenece a un grupo (colectivo) que ningún acto voluntario puede disolver (Arendt 2007b 152153). Así hablamos de responsabilidad política, tanto cuando una comunidad

\footnotetext{
${ }^{2}$ Esto ocurre, pues vivimos en un mundo político que existió antes que nosotros llegáramos a él y que continuará existiendo cuando muramos, lo que nos hace establecer lazos humanos complejos, que no se pueden disolver voluntariamente (como ocurre con la comunidad política en la que nacemos) y que se extienden más allá del tiempo y del espacio inmediato.
} 
asume responsabilidad por lo que ha hecho uno de sus miembros, como cuando una comunidad es responsable por lo que se ha hecho en su nombre (Arendt 2007b 153). De este modo, en una comunidad política cada generación debe cargar con las injusticias cometidas por sus antecesores en la misma medida en que se beneficia de los actos de éstos. Así es como cada individuo, así como cada generación, se hace cargo de la historia de la comunidad a la que pertenece. Con la descripción recientemente dada, nos podemos dar cuenta de que las responsabilidades colectivas no son punibles: las comunidades no se pueden llevar frente a los tribunales, así como tampoco son las comunidades ni su historia las que realizan crímenes.

Ahora, la responsabilidad individual o personal nos puede producir confusiones. A quienes les atribuímos una responsabilidad personal frente a un crímen, es porque pueden haber sido cómplices de aquel crimen, pero no sabiendo que se estaban cometiendo ni que estaban siendo cómplices de quienes los cometían (Arendt 2007b 62), es decir, se le atribuye esta responsabilidad a quienes han participado de un crimen pero cuya participación no se ha realizado bajo conocimiento ni consentimiento. Acá las personas son responsables moralmente, pero no se les puede llevar a un tribunal sólo por ello.

Si bien comúnmente se busca evadir la culpa y disfrazarla de responsabilidad (una de las formas más claras de esta elusión es a través de expresiones "yo no sabía" o "fui obligado") Arendt es enfática al decir que, finalmente existe una instancia donde sólo acuden los culpables en sentido estricto, y es el lugar donde esta culpa se logra probar y dictar un castigo. Esta instancia es el tribunal, un lugar donde todas las justificaciones de la naturaleza se derrumban, donde no se juzgan los "ismos" ni el pecado original, sino los seres humanos de carne y hueso.

Para nuestra filósofa es necesario otorgar un castigo a los crímenes realizados, pues nuestro sentido de justicia nos lo exige. Y este castigo va más allá de la venganza -como vimos- ya que la ley y el castigo se crean con el fin de romper el círculo vicioso de ella (Arendt 2007b 56). Finalmente es el tribunal, sobre la base de las leyes creadas en representación de una comunidad política y esto acorde al acuerdo fundamental que crea una comunidad política (Constitución), quien determina, si un ser humano es culpable o no, y qué castigo se debe aplicar a la falta que cometió.

Ahora, nos queda preguntarnos ¿por qué es esa la instancia donde llevamos los crímenes y a quienes los cometieron? ¿Qué hay en el ser humano que hace que surja su sentido de justicia? A mi parecer se trata aquí de la facultad de juzgar. 


\section{Facultad de juzgar}

En sus escritos Arendt trata de separar aguas entre lo que es la política y el pensamiento, pero también rescata la incursión de este último en la política a propósito de la reflexión que surge del seguimiento que ella hizo al juicio de Adolf Eichmann, realizado en 1961 en Jerusalén. De ese seguimiento surge el texto Eichmann en Jerusalén, en el cual la autora esboza la noción de «mal banal», para referirse al caso particular de los hombres como Eichmann que, sin tener «mal corazón», fueron capaces de un mal incomparable en la historia.

En el artículo El pensar y las reflexiones morales Arendt nos dice que Eichmann no era un monstruo, ni estaba imbuido de maldad, más bien sufría de una obediencia ciega y una incapacidad de cuestionamiento de lo que ocurría a su alrededor, a tal nivel que aceptaba y se adaptaba a la subversión de normas que se le imponía (Arendt 2008a 109). Y si bien Eichmann cometió crímenes en un momento donde el crimen se había legalizado y las normas morales se habían invertido, aún así no puede evadir su responsabilidad $\mathrm{y}$, sobre todo, su culpabilidad en los crímenes realizados. Arendt afirma que siempre los seres humanos tienen la capacidad de abstraerse de las leyes del momento y los supuestos que las rodean, y pueden distinguir entre el bien y el mal. Esta capacidad es independiente de la instrucción, la clase social y la inteligencia (Boella 2000 179), pues tiene que ver con la capacidad de pensar que todo hombre en su sano juicio posee (Arendt 2008a 114). Así usando términos kantianos, Arendt nos dice que para prevenir el mal se necesita la filosofía, el ejercicio de razón como facultad de pensamiento (Arendt 2008a 115). Esta capacidad de distinguir el bien del mal es propia de la facultad de juzgar, que es una forma de pensamiento: un pensamiento político, es decir que tiene que ver con la opinión, que se caracteriza "por la movilidad imaginativa y la capacidad para representar la perspectiva de los otros" (Villa 1999 96-97). Richard Bernstein nos dice que esta formación de opinión, que corresponde al pensamiento político es un "«genuino encuentro con diferentes opiniones» lo que sólo puede ocurrir al interior de «una comunidad política de iguales»" (Bernstein 1986 citado por Villa 1999 97).

Ahora bien, cuando Arendt se refiere al juicio como un «pensar sin barandas», está esbozando de alguna forma que, para poder llegar a juzgar es necesario deshacerse de ciertas determinaciones. Este paso previo al juicio, que consiste en eliminar las preconcepciones que limitan el juicio y le impiden ser independiente, es el pensar.

En El pensar y las reflexiones morales Arendt destaca las características destructivas del pensar: por sí mismo no pone en marcha creencias nuevas, ni crea valores, ni "descubrirá, de una vez por todas, lo que es «el bien», y no confirma, 
sino más bien disuelve las reglas establecidas de conductas" (Arendt 2008a 136). Pero es este carácter destructivo del pensar lo que permite liberarse de todo lo que tienda a determinar previamente el juicio, y que le impida efectuar su discernimiento «sin barandas». Es luego del pensar destructivo, y gracias a él, que se abre paso a la facultad de juicio, que no necesita nociones previas para poder emitir un juicio sobre lo bueno y lo malo: si lo normal es que los hombres nos guiemos por la norma y subsumamos bajo ella todos los actos particulares que se realizan (nos guiamos a partir de los juicios que Kant llama determinantes), es la facultad de juzgar la que nos permite, cuando todas las normas se muestran dignas de duda, tomar los eventos particulares y elevar a través de ellos una ley general. De este modo, si el pensar destruye nuestras creencias y prejuicios, y por lo mismo se le considera peligroso, mucho más peligroso para la política es no pensar, pues impide a los seres humanos tomar decisiones y los lleva a que puedan adherir inmediatamente, y sin ningún tipo de cuestionamientos, a cualquier conjunto de normas que una sociedad imponga en un momento determinado.

En Arendt el pensamiento cumple la labor fundamental de permitirle al ser humano apartarse de todas las determinaciones y preconcepciones no examinadas que limitan su acción, y es esta destrucción la que permite liberar y poner en acción la facultad política por excelencia: la facultad de juzgar.

Esta capacidad de juzgar o «pensar sin determinaciones» que tenemos todos los seres humanos, sólo se manifiesta en casos excepcionales en ciertos seres humanos. Pero ¿por qué, si todos los seres humanos tienen la capacidad de juicio, ésta sólo aflora en casos excepcionales? Al parecer sería porque, en general, los seres humanos evaden el juicio, por la incomodidad que éste produce al obligar a un enfrentamiento del yo consigo mismo en una suerte de diálogo escudriñador ${ }^{3}$. La incapacidad de pensamiento reflexivo -del pensar dialogando solo consigo mismo y sin depender de leyes o principios externos- esto es, la incapacidad de hacer uso de la facultad de juicio ${ }^{4}$ es de lo que Arendt acusa a Eichmann, pues si él, $\mathrm{y}$ muchos otros, hubiesen pensado y hubiesen juzgado los acontecimientos

\footnotetext{
3 Cito el caso narrado por Simon Leys (2011) en "Mentiras verdaderas", uno de los ensayos reunidos en La felicidad de los pececillos. Ahí él recuerda la historia del periodista y escritor alemán Sebastian Haffner, quien, en la parte de sus memorias dedicada a los años previos a la Segunda Guerra Mundial, cuenta el proceso que lo llevó a dejar su país tras presenciar el ascenso de Hitler al poder: sin ser testigo de ninguna crueldad que no supiera cualquiera, viviendo la misma realidad que todos los alemanes, Haffner se autoexilió a Francia y luego a Inglaterra. Frente a esta historia Leys se hace la pregunta: $\mathrm{Si}$ este hombre sabía lo mismo que millones de alemanes: ¿Por qué no hubo más que un solo Haffner? (Rodríguez, J. 2015 "Dóciles y obedientes: la normalidad del mal. Entrevista a Simona Forti". Paralaje № 12 147). El caso narrado por Leys da cuenta de la excepcionalidad de la capacidad de juzgar.

${ }^{4}$ Ahondaremos en este punto más adelante.
} 
ocurridos al interior de la Alemania nazi, y su participación en esos acontecimientos, se habrían podido prevenir los grandes crímenes del totalitarismo. Si bien Eichmann actuó bajo la legalidad que existió en la Alemania nazi, eso no lo exculpa, pues siempre pudo haber puesto a andar su facultad de juzgar, la cual existe en el interior de cualquier ser humano.

Al parecer para Arendt la facultad de juzgar está en la base de las relaciones políticas. Se supone que todas las personas son capaces del juicio y a ello hay que apelar en última instancia al momento de establecer responsabilidades así como también culpas frente a los agravios y las injusticias que se cometen en el mundo de los asuntos humanos: Eichmann fue condenado a la horca porque, estando dotado de juicio no fue capaz de pensar políticamente, y quien, por no pensar políticamente es capaz de cometer tan graves crímenes, debe ser declarado culpable, por no estar apto para compartir el mundo político con otros y porque su falta de juicio lo puede llevar a destruir ese mundo político ${ }^{5}$. Los seres humanos, por ser seres políticos, deben tener y usar la facultad de juzgar en momentos políticos críticos; por lo mismo las instituciones políticas, como los tribunales, suponen la existencia y el uso del juicio.

\section{El juicio legal y el castigo}

De este modo es que los tribunales y los juicios legales que se llevan a cabo en su interior suponen la facultad de juzgar que tenemos los seres humanos y a la cual deberíamos recurrir en situaciones extremas, así como también suponen y resguardan la promesa que implica la ley y resguardan la posibilidad de reconciliación de la comunidad política.

La acción y el discurso y sus características efímeras y frágiles, es lo que nos impulsa a construir la vida en comunidad y a organizarnos políticamente para darle a la política una mayor estabilidad y permanencia. $Y$ es esta permanencia lo que abre paso a la noción de justicia. Pero también hay que tener en cuenta que es la misma acción, en su calidad de irreversible e imprevisible, la que puede producir agravios e injusticias. Tal como dijimos en párrafos anteriores la injusticia es una posibilidad que existe porque los hombres actúan, y esta acción pertenece al mundo público, por lo tanto la injusticia no existe al interior de los hombres sino que en su exterior: no hay hombres injustos sino actos injustos. Pero al interior de la misma pluralidad de seres humanos surge nuestro sentido de justicia y la forma de poder remediar los agravios que se producen en nuestro mundo humano. La

\footnotetext{
${ }^{5} \mathrm{~A}$ través de la condena que Arendt hace a Eichmann en su texto, pareciera que ella estuviera de acuerdo con la pena de muerte para estos casos extremos. Más allá de mostrar la evidente polémica, este es un aspecto del cual no nos haremos cargo en este trabajo.
} 
justicia es una virtud cívica, que ya Aristóteles definía como el orden de la comunidad civil (Aristóteles 2000 53). Así se muestra la relación que existe entre ley (la «herramienta» por medio de la cual se realiza la justicia), juicio (el acto de aplicar la ley y realizar la justicia) y la comunidad: "la ley presupone precisamente que existe una comunidad en lo humano con aquellos a quienes acusamos, juzgamos y condenamos" (Arendt 2008b 366). Particularmente, la importancia de la ley radica en que ella puede remediar la imprevisibilidad de la acción al interior de la comunidad política: hay cosas que no están permitidas hacer y todos lo sabemos, por lo tanto aspiramos a que nadie actúe de esta forma y quien lo haga recibirá una sanción ya estipulada.

Sin pretender profundizar en terrenos del derecho, digamos -porque interesa al tema de este artículo- que a grandes rasgos hay dos tipos de agravios que se cometen en una comunidad humana y, por lo tanto, dos tipos de juicios legales a los que se someten estos agravios: por un lado están los agravios civiles, que son los agravios se produce un daño hacia una persona en particular (una víctima). Frente a estos agravios, lo que se busca en los tribunales civiles es la compensación de la víctima. En cambio en los agravios que son de carácter penal, la afrenta no es realizada hacia un individuo o un grupo de ellos, sino hacia la comunidad política en su totalidad, pues son las relaciones politicas humanas las que se están poniendo en tela de juicio. En los juicios penales, mediante la acción de la justicia no se repara al individuo violentado, sino al cuerpo político y al orden público en general, pues es lo que ha sido perturbado y debe ser restablecido (Arendt 2008b 380-381).

De esta forma, lo importante para nuestro tema es el juicio penal, es decir, aquel en que se está jugando la posibilidad del espacio público y de la comunidad política. Lograr establecer culpables y otorgarles un castigo según sus culpas, apela a la reparación de un espacio político que se fracturó por un agravio, apela a la restauración de la promesa política que es la ley: sólo si un crimen se castiga podemos prever y tener confianza en que esta promesa sigue en pie, y que es posible establecer o, en este caso, restablecer, este espacio común en donde nuestros deberes y derechos se conocen de antemano.

Precisamente, y como hemos visto, en los tribunales no se juzgan sistemas, tendencias ni pecados originales, sino hombres de carne y hueso, individuos, cuyos actos son actos humanos: estos hombres comparecen ante un tribunal porque han infringido alguna ley cuyo mantenimiento consideramos esencial para la integridad de nuestra común humanidad (Arendt 2007b 52-53). Es esta persona a quien se le declara culpable por su participación en los hechos, y según esa culpabilidad se le otorga un castigo. El castigo, entonces, es la forma legal (bajo los parámetros de las normas de la comunidad) que pone fin a una acción injusta que 
de otra forma, por las características propias de la acción que anteriormente mencionamos (irreversibilidad e impredecibilidad), no tendría fin (Arendt 2005a 260). De no ser por el castigo, una serie de acontecimientos ligados a la acción agraviante continuarían ocurriendo, lo que pondría en riesgo la comunidad y la política.

Incluso en un caso como el de Eichmann, donde el inculpado alegaba ser parte de una estructura de dominación, como lo fue el totalitarismo nazi, dentro de la cual le era imposible saber la verdad de lo que ocurría, la real autoridad, y los fines que se perseguían con los crímenes; aún así, Eichmann, que con ello buscaba exculparse, en cuanto persona no podía eludir su culpa en los actos efectuados, porque siendo humano era un ser dotado de juicio -la más política de las habilidades mentales (Bernstein 2004 312)-, lo que le permitía distinguir entre lo bueno y lo malo.

Precisamente por esa inhabilidad de pensar y de juzgar que Arendt identifica en Eichmann -lo que finalmente representa una incapacidad de desenvolverse en un mundo humano (mundo político) donde la existencia de la pluralidad de hombres es condición-, es que ella cree que el castigo al que debe ser condenado es la horca (Arendt 2008b 436), es decir, no formar parte del mundo humano.

Si bien podemos considerar que en el acto de castigar a un culpable -sobre todo en el condenarlo a la horca- existe cierta violencia, la cual Arendt se ha esforzado de sacar del ámbito político, Arendt misma en Sobre la violencia nos revela que, aunque la violencia no es política, sí puede estar al servicio de ella, pues posee un carácter instrumental (2008c 63), claro que siempre debe ser guiada de forma medida y racional (2008c 63). Así, identificamos el castigo como un instrumento de la política para mantener el espacio público. Este instrumento no es infalible y no logra levantar precedentes para que un crimen no se repita nuevamente (Arendt 2008b 397-398), pero desde un punto de vista político esto no es relevante, pues, el castigo no tiene una finalidad ejemplificadora o preventiva del delito, sino que, insistimos, busca asegurar la comunidad política, restaurarla y declarar firmemente que es posible mantenerla.

En definitiva, los juicios legales y las condenas que de ellos se desprenden se sustentan en la existencia de una ley, la cual, a su vez presupone que existe una comunidad, con aquellos a quienes juzgamos legalmente (Arendt 2008b 366), y dentro de esta comunidad una igualdad que hace que la ley alcance a todos. Los hombres no somos iguales por naturaleza, sino que gracias a la construcción de una comunidad política, y sólo al interior de ella nos volvemos iguales (Benhabib 2005 citando a Arendt 1968). Esta construcción de comunidad es lo que nos lleva a instaurar una ley que rija para todos y que garantice los derechos y el 
cumplimiento de los deberes al interior de ella, es decir establece los límites de acción de los hombres que pertenecen a esta unidad.

Entonces, ¿a qué nos puede llevar la impunidad? El no castigar crímenes o el no exculpar sobre la base de un juicio legal y de las leyes puede llevar a un eternizamiento de los conflictos y a una fisura en la comunidad. De esto un ejemplo: las violaciones a los derechos humanos en la dictadura chilena.

Si miramos el caso chileno, nos percatamos de que la falta de juicio legal y castigo a quienes son culpables de los crímenes cometidos durante la dictadura cívico-militar, entre otros factores, ha cooperado en mantener una fractura social silenciosa, que se asoma ante provocaciones mínimas, como fue durante 2009 y 2010, así como también al año 2016, el probable indulto a los condenados por violaciones a los derechos humanos, o la discusión generada durante el segundo gobierno de Michelle Bachelet respecto al cierre de Punta Peuco. Este caso muestra que, más allá de que los acontecimientos no sean vividos de igual forma por los actores involucrados ni observados de igual forma por los espectadores de los acontecimientos, aún así, hay un hecho objetivo que ocurrió, y frente al cual, la ley de la comunidad nos podrá decir si es un crimen o no. Reconocer esto es un acto que resguarda nuestra comunidad, que es lo que continuamos compartiendo más allá de las diversas perspectivas.

\section{Bibliografía}

Arendt, Hannah. "Verdad y Política”. En Entre el pasado y el futuro. Ocho ejercicios sobre la reflexión política. Barcelona: Península, 1996.

Arendt, Hannah. La condición humana. Barcelona: Paidós, 2005a.

Arendt, Hannah. “Culpa organizada”. En La tradición oculta (35-47). Buenos Aires: Paidós, 2005b

Arendt, Hannah. Diario filosófico 1950-1973. Barceloa: Herder, 2006.

Arendt, Hannah. "Responsabilidad personal en una dictadura”. En Responsabilidad y juicio (49-74). Barcelona: Paidós, 2007b.

Arendt, Hannah. "Responsabilidad colectiva”. En Responsabilidad y juicio (151-159). Barcelona: Paidós, 2007a.

Arendt, Hannah. "El pensar y las reflexiones morales". En De la historia a la acción (109-137). Buenos Aides: Paidós, 2008a.

Arendt, Hannah. Eichmann en Jerusalén. Barcelona: Debolsillo, 2008 b. 
Arendt, Hannah. Sobre la violencia. Madrid: Alianza, 2008c.

Aristóteles. Política. Madrid: Gredos. 2000.

Benhabib, Seyla. "El derecho a tener derechos: Hannah Arendt y las contradicciones del Estado-nación". En Los derechos de los otros (45-60). Barcelona: Gedisa, 2005.

Bernstein, Richard. "Arendt: El mal radical y la banalidad del mal". En El mal radical (285-314). Buenos Aires: Lilmod, 2004.

Boelle, Laura. ¿Qué significa pensar políticamente? En Birulés, Fina (Comp.), Hannah Arendt. El orgullo de pensar (235-257). Barcelona: Gedisa, 2000.

Leys, Simon. La felicidad de los pececillos. Cartas desde las antípodas (traducción de José Ramón Monreal). Barcelona: Acantilado, 2011.

Rodríguez, Juan. "Dóciles y obedientes: la normalidad del mal. Entrevista a Simona Forti". Parajaje N¹2, 2015.

Villa, Dana. "Thinking and Judging". En Politiscs, philosophy, terror. Essays on the thought of Hannah Arendt (86-106). New Jersey: Princeton University Press, 1999. 